\title{
Editorial
}

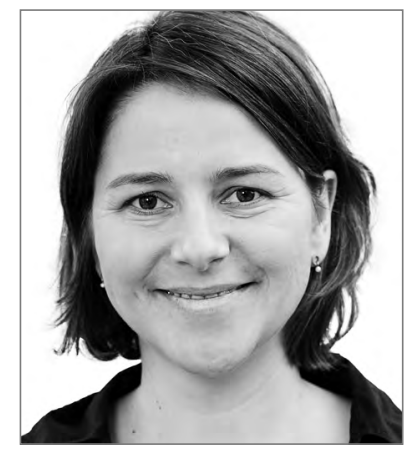

\section{LINDA NIERLING}

Institut für Technikfolgenabschätzung und Systemanalyse (ITAS), Karlsruhe (linda.nierling@kit.edu) n Zeiten des Social Distancing, dem Gebot der Stunde in der Corona-Pandemie, haben sich gezwungenermaßen neue Arbeits-, Lebens- und Lernformen sowie Alltagsroutinen entwickelt. Öffentliche Räume aber auch die Rolle des „Zuhauses“ werden anders. Davon sind Städte ganz unmittelbar betroffen: veränderte Energiebedarfe und Mobilitätsmuster, Ansprüche an und die Nutzung von städtischen Räumen, Verfügbarkeit von Internet und die Erkenntnis, dass soziale Teilhabe heute ohne Zweifel eine digitale Teilhabe umfasst und dafür auch von Städten neue Infrastrukturen geschaffen werden müssen, z. B. um Bildung und auch mobile Arbeitsformen zeitgemäß ermöglichen zu können.

Durch Social Distancing sind zudem veränderte soziale Interaktionsformen entstanden. In öffentlichen Debatten wird hierzu der Begriff der Solidarität sehr oft als normative Orientierung verwendet. Zum Begriff der Solidarität gibt es eine lange Begriffsgeschichte, sie begründet sich in aller Kürze bei Durkheim und wird z. B. bei Marcel Mauss oder Axel Honneth weitergeführt. Wie der Soziologe Sighard Neckel kürzlich sagte, sieht solidarisches Handeln vom Eigeninteresse ab und basiert vielmehr darauf, auf Wechselseitigkeit zu vertrauen. Die Anerkennung stiftende Partizipation am gesellschaftlichen Leistungsaustausch, das Geben und Nehmen, und letztlich die Einsicht, dass Gesellschaft auf einem Prinzip der Gegenseitigkeit beruht, führt dazu, dass Solidaritätsprinzipien immer auch institutionell verankert werden, mit dem Ziel, als Gesellschaft gerade auch bei Krisen gewappnet zu sein.

Im Angesicht der pandemiebedingten Erschwerung von Arbeits- und Alltagsroutinen finden sich Akte der gegenseitigen Solidarität auch in der Technikfolgenabschätzung, wenn z. B. trotz der bekannten Implikationen der Krise Beiträge für die Zeitschrift TATuP fristgerecht eingereicht, in der vorgegebenen Zeit begutachtet und überarbeitet werden.

Mit dieser Ausgabe von TATuP beginnt der 30. Jahrgang der Zeitschrift! Insbesondere in Zeiten des Social Distancing erweist sich TATuP für die TA-Community über ihre wissenschaftlichen Inhalte hinaus auch als eine Plattform für Diskussion und wechselseitigen Austausch im Vertrauen darauf, dass es Formate der direkten und persönlichen Interaktion in Zukunft wieder geben wird.

\section{Linda Nierling}

